\title{
Complexo econômico e complexidade econômica: originalidade e atualidade em Wilson Cano *
}

\author{
Bernardo Campolina ${ }^{* *}, * * *$
Clélio Campolina Diniz
}

\section{Resumo}

Este artigo analisa a contribuição teórica e metodológica de Wilson Cano no que diz respeito ao conceito de complexo econômico para interpretar o desenvolvimento econômico do Brasil e seus resultados ou impactos diferenciados no território. Para ele, o complexo, criado e induzido pela cafeicultura do planalto paulista, e sua capacidade de diversificação e inter-relação setorial, constitui a base para a interpretação do processo de crescimento e concentração industrial naquele estado. Por contraste, resgata as principais experiências históricas, a saber: produção de açúcar no nordeste brasileiro, extração de borracha na região amazônica, agricultura dispersa nos três estados do Sul, cafeicultura escravista do vale do paraíba e do leste mineiro e extração de ouro no século XVIII. Demonstra que nessas regiões não estavam presentes as condições necessárias à indução de um processo virtuoso de industrialização com criação de uma estrutura econômica diversa e complexa. Por último, apresentamos um contraponto entre a formulação teórica proposta por Cano (1977) e a recente metodologia da complexidade econômica proposta por Hausmann e Hidalgo (2011). Procuramos demonstrar a originalidade e riqueza de Cano (1977) que, a despeito da falta de dados e sistemas computacionais, continua sendo atual para pensar os desafios ligados aos processos de desenvolvimento, especialmente em países de grande dimensão e diversidade territorial, por incluir também as condicionantes internacionais, institucionais, sociais e políticas.

Palavras chave: Cano, Wilson, 1937-2020, Complexo econômico, Complexidade, Desenvolvimento industrial.

\section{Abstract \\ Economic complex and economic complexity: originality and topicality in Wilson Cano}

This article analyzes Wilson Cano's theoretical and methodological contribution regarding the concept of the economic complex to interpret Brazil's economic development and its results or differentiated impacts on the territory. The coffee economy created and induced by the coffee plantation in the São Paulo Plateau, and its capacity for diversification and sectorial interrelationship constitutes the basis for the interpretation of the process of industrial growth and concentration in São Paulo. By contrast, the author analyzes the main historical events, namely: sugar production in the Brazilian northeast; rubber extraction in the Amazon region; dispersed agriculture in the three southern states; coffee plantations driven by slave labor in the Paraíba Valley and eastern Minas Gerais; and gold extraction in the 18th century, in order to demonstrate that these regions did not have the necessary conditions to induce a virtuous process of industrialization with the creation of a diverse and complex economic structure. Finally, we present a counterpoint between the theoretical formulation proposed by Cano (1977) and the recent methodology of economic complexity proposed by Hausmann and Hidalgo (2011), to demonstrate the originality and richness of Cano's (1977) contribution. Despite missing data and the fact that computer

\footnotetext{
* Artigo recebido em 31 de março de 2021 e aprovado em 18 de julho de 2021.

${ }^{* *}$ Professor Associado do Centro de Desenvolvimento e Planejamento Regional (Cedeplar), Belo Horizonte, MG, Brasil. E-mail: bcampolina@cedeplar.ufmg.br. ORCID: https://orcid.org/0000-0002-2728-3309.

${ }^{* * *}$ Professor do Departamento de Ciências Econômicas da Universidade Federal de Minas Gerais (UFMG), Belo Horizonte, MG, Brasil.

**** Professor Emérito da Faculdade de Ciências Econômicas da Universidade Federal de Minas Gerais (UFMG), Belo Horizonte, MG, Brasil. E-mail: cleliocampolina@gmail.com._ORCID: http://orcid.org/0000-0001-9703-890X.
} 
systems were not yet available, Cano's analysis is still current when one considers the challenges related to development processes, particularly in large, diverse countries, considering the international, institutional, social, and political dimensions.

Keywords: Cano, Wilson, 1937-2020, Economic complex, Economic complexity, Development industrial. JEL R00, O1, P5.

\section{Introdução}

O objetivo principal deste artigo é analisar e resgatar a contribuição de Wilson Cano na formulação do conceito de complexo econômico e sua utilização para a interpretação do desenvolvimento brasileiro e seus impactos regionais diferenciados. Mostra a riqueza do trabalho do autor e sua atualidade para pensar a trajetória recente do desenvolvimento regional brasileiro. A despeito da ausência de uma modelagem formal e de um grande volume de dados, considera também os condicionantes internacionais, institucionais, sociais e políticos como elementos fundamentais para se pensar em um processo de diversificação e integração, o que não está explícito na metodologia da complexidade.

Além desta introdução, o trabalho tem mais quatro seções. Na primeira seção resgata-se o conceito de complexo econômico da cafeicultura paulista formulado por Cano, o que demonstra como este promoveu o desenvolvimento econômico do estado, sua industrialização e sua concentração, transformando aquele estado no motor industrial e econômico do país. Na segunda seção, de forma análoga, e tomando o mesmo conceito, Cano (1977) procura apontar as limitações para o surgimento e formação de outros complexos econômicos regionais no país. Discute e aponta as razões econômicas, políticas e sociais para explicar o atraso do Nordeste, do Sul, da região Amazônica e de Minas Gerais. A análise feita por Cano abarca o período que vai do final do século XIX até a década de 1940, quando a Região Metropolitana de São Paulo atingiu 45\% da produção industrial do país. Análise posterior (Cano, 1985) indicou que essa concentração continuou se ampliando, até atingir seu pico em 1970, com 58\% da produção industrial do país. Na terceira seção, Diniz (1993) tomando como referência a integração industrial regional procura apontar as razões para o início da desconcentração industrial paulista, induzida por políticas públicas e decisões empresariais, alargando o complexo econômico paulista que levaria à constituição do polígono industrial brasileiro

A quarta seção discute a atualidade do conceito de complexo econômico proposto por Cano (1977) procurando apontar como os avanços metodológicos recentes, em especial aqueles ligados à complexidade econômica e a ideia de product space (Haussman; Hidalgo, 2011) representaram um avanço no que diz respeito à mensuração das interconexões setoriais e regionais, mas ao mesmo tempo empobrece, analiticamente, o conceito de complexo econômico, ao não se considerar o mercado interno em países de grande dimensão territorial, os aspectos institucionais, sociais e políticos e a própria política industrial e de inovação para o caso brasileiro, e de outros países com características semelhantes. 


\section{O conceito de complexo econômico em Wilson Cano}

Partindo das concepções teóricas e metodológicas dos efeitos e impactos do comércio e das relações intersetoriais consagrados na literatura ${ }^{1}$, Cano agrega os condicionantes internacionais, sociais, políticos e institucionais para a análise da dinâmica econômica do Brasil e seus resultados ou impactos diferenciados no território.

No início do livro "Raízes da Concentração Industrial em São Paulo" (1977), Cano começa definindo e caracterizando o que ele entende por complexo econômico cafeeiro do planalto paulista, seus componentes, suas caraterísticas e seu papel no desenvolvimento de São Paulo. Para ele, o complexo se iniciou com a atividade cafeeira no planalto paulista, através do qual foram sendo agregadas novas atividades que se interrelacionavam, formando um conjunto de oito, a saber: a) atividade produtora de café; b) agricultura mercantil de alimentos; c) atividade industrial; d) sistema ferroviário; e) sistema bancário; f) atividades de exportação e importação; g) infraestrutura portuária e urbana e; h) atividades públicas.

Além dessas oito atividades, lista cinco condicionantes que facilitaram o desenvolvimento econômico do estado, a saber: atração de imigrantes; disponibilidade de terras planas e com alta fertilidade; saldo na balança comercial; atração de capital externo; políticas de valorização do café, especialmente manutenção de preços e demanda, sistema tarifário e cambial.

A interação entre esse conjunto de atividades promoveu a expansão, diversificação e integração entre elas, gerando um efeito econômico dinâmico, induzindo o crescimento industrial e sua concentração no estado, especialmente no que atualmente forma sua área metropolitana ${ }^{2}$.

\subsection{O complexo cafeeiro capitalista e a concentração industrial em São Paulo}

Para Cano, o café implantado no oeste paulista foi a atividade principal e dominante, entre a década de 1880 e a crise de 1929. Dada a existência de demanda internacional, seu sucesso diferenciado decorreu da existência de terras planas e com alta fertilidade e, consequentemente, maior produtividade, comparativamente ao café que vinha sendo produzido no vale do paraíba e no leste de Minas Gerais. Esse crescimento não foi, no entanto, contínuo e regular. Isto porque as variações de preço estimulavam ou desestimulavam novos plantios. Nesse sentido, as diferentes políticas públicas foram decisivas para atenuar as flutuações de preços e de demanda internacional, através da compra de excedentes ou manutenção dos preços, garantindo a expansão e consolidação da atividade.

O segundo fator indutor do dinamismo da cafeicultura naquela região foi a introdução do trabalho assalariado, viabilizado pela chegada dos imigrantes estrangeiros, especialmente italianos e, posteriormente, japoneses e nacionais, vindos do Nordeste e de Minas Gerais. O trabalho assalariado na cafeicultura, as atividades de exportação e importação e de outros serviços urbanos ampliaram a demanda de alimentos, induzindo a expansão da agricultura mercantil de alimentos.

(1) Guilhoto (2015) resgata a importância do comércio e das relações interindustriais desde os autores considerados percursores da economia, como de Cantillon (1755), Quesnay (1758), Leontief (1941) e seus desdobramentos posteriores.

(2) Para uma análise da aplicação do conceito econômico de Wilson Cano e sua aplicação a outras regiões do país, veja também Vieira (2021). 
Por sua vez, o crescimento da produção de café e a agricultura mercantil de alimentos estimulou a implantação de ferrovias, fator decisivo para facilitar e reduzir custos de transporte. Destaca-se que dada a demanda sustentada de transportes, o sistema ferroviário paulista foi sempre superavitário, gerando excedentes que facilitavam a ampliação da malha ou a diversificação produtiva, especialmente em atividades industriais e urbanas, em contraste com outras experiências regionais no Brasil.

O efeito conjunto do crescimento da produção de café, das atividades de exportação e importação, da agricultura mercantil de alimentos, da infraestrutura de transportes ferroviária e portuária, promoveram e estimularam o desenvolvimento das atividades urbanas, com destaque para a criação de bancos, comércio exterior e local, sistema de armazenagem, energia elétrica, construção civil, transporte urbano e atividades industriais. Nesse último caso, destaca-se as oficinas de montagem e manutenção ferroviária, a chegada de empresas estrangeiras como a Light, as montadoras Ford e GM, a Bayer e a Krupp. Foram também criadas várias empresas nacionais, a exemplo da Matarazzo, Pirelli, Antártica e de indústrias diversas para a produção de equipamentos agrícolas, de beneficiamento de café, embalagens, açúcar, têxtil, papel, cerveja, cimento, vidro, entre outras.

$\mathrm{O}$ impacto conjunto dessas atividades gerou efeitos inter-relacionados, economias de escala e externas, promovendo a redução de custos de produção, aumento da produtividade e geração de excedentes, permitindo a ampliação e diversificação de novos investimentos, ampliando o mercado e realimentando o processo.

Como consequência, ocorreu o crescimento da indústria paulista, a qual ampliou sua participação na produção nacional de 15,9\%, em 1907, primeiro ano para o qual há estatísticas comparativas no Brasil, para 31,5\% em 1919, 37,5\% em 1929 e 45,4\% em 1939, último ano no período inicialmente analisado por Cano.

A força desse crescimento e seus efeitos inter-relacionados promoveu, também, uma concentração ainda maior dos segmentos das indústrias tecnologicamente mais complexas em São Paulo, como equipamentos e material elétrico, metalmecânica e química, consolidando sua liderança nacional.

Em “Desequilíbrios Regionais e Concentração Industrial em São Paulo 1930-70”, publicado em 1985, Cano resgata as análises anteriores e avança na interpretação das transformações ocorridas nesse período. Demonstra que a participação de São Paulo na produção industrial brasileira atingiu $58 \%$ em 1970, sendo que $76 \%$ desta estava na RMSP, que correspondia a $44 \%$ da produção nacional.

\section{A formação da grande periferia brasileira}

\subsection{Condicionantes do atraso econômico nordestino}

Para o Nordeste do Brasil, primeira região efetivamente ocupada pelos colonizadores portugueses, resgatando a análise de Furtado (1959), Cano (1977) demonstra que as atividades produtoras de açúcar, ainda na primeira metade do século XVI, foi feita através da concessão de sesmarias, trabalho escravo e do exclusivo comercial com a metrópole. O impedimento de acesso à terra e a escravidão não permitiram o desenvolvimento de uma agricultura mercantil de alimentos, bem como de um mercado interno, base para a diversificação produtiva. O excedente era dividido 
entre a importação de equipamentos para os engenhos, consumido pela elite local como bens de consumo importados, ou transferido para a metrópole.

Na primeira metade do século XVII a região foi ocupada pelos holandeses, que assumiram o controle do comércio e assimilaram as técnicas de produção. Ao serem expulsos, na segunda metade do século, eles desenvolveram a produção na região do caribe, estabelecendo forte concorrência, provocando queda nos preços e redução da produção e das exportações brasileiras. Com a crise, parcela da população emigrou para o interior semiárido da região, como agregados dos proprietários de terra, em uma situação de quase servidão ou de subsistência como meeiros dos proprietários de terra.

A partir do final do século XVII, a descoberta do ouro e, posteriormente, de diamante em Minas Gerais e seu avanço em direção a Goiás criou oportunidades para a metrópole, deslocando o foco dos interesses, implicando, inclusive, a transferência da capital da colônia de Salvador para o Rio de Janeiro e de escravos para a região das minas. No século XIX, a expansão da cafeicultura no sudeste do país e a extração de borracha na região amazônica passaram a ser alternativas econômicas exportadoras desviando uma vez mais o foco econômico da Região Nordeste. No caso da Amazônia houve inclusive à criação do exército da borracha, através da transferência de levas de nordestinos para a região.

Mesmo o plantio e exportação de algodão do Maranhão, de grande sucesso no século XIX, logo encontrou a concorrência americana e internacional, provocando a redução dos preços e a queda da produção. Após sua decadência, continuou sendo cultivado no vasto semiárido nordestino, através de espécie permanente, por colonos. Estes entregavam a produção aos proprietários de terra, em troca de uma agricultura de subsistência, consolidando a situação de miséria. Adicionalmente, parcela da população nordestina se deslocou no sentido sul, através do Rio São Francisco, povoando suas margens.

A implantação de ferroviárias na região, a partir da segunda metade do século XIX, era predominantemente de propriedade estrangeira, com garantia de rentabilidade, ou através de empréstimos com garantia de juros. Os vários ramais implantados em regiões onde não havia nenhuma atividade produtiva de destaque e demanda de transportes, operou sempre em situação deficitária. Essa situação onerava os cofres públicos, pois as empresas estrangeiras tinham em seus contratos garantia de rentabilidade. A encampação pública do sistema ampliou, ainda mais, o ônus para os cofres públicos (Castro, 1979; Siqueira, 2002).

Nessas condições, as diferentes etapas históricas e as atividades produtivas no Nordeste não permitiram a formação de um complexo econômico regional e, portanto, não houve dinamismo, estabelecendo os traços do atraso econômico da região, que persiste até os dias de hoje.

\subsection{A frustrada expansão econômica da região amazônica}

A exploração da borracha na região amazônica tampouco criou as condições para a integração produtiva e o dinamismo na região. A produção era organizada pelo regime de aviamento, através do qual as casas exportadoras e importadoras, predominantemente de capital britânico, compravam a produção e forneciam os bens de subsistência aos trabalhadores e os bens de consumo mais 
sofisticados para a elite local, criando um verdadeiro monopsônio nas compras e um monopólio nas vendas.

O sistema de aviamento, as dificuldades ecológicas e climáticas, a grande extensão da região, e a dispersão da exploração da borracha dificultavam também a integração produtiva e o desenvolvimento de uma agricultura mercantil de alimentos. O sistema de transportes fluvial monopolizado constituiu outro entrave ${ }^{3}$.

O monopólio estrangeiro do comércio e dos transportes das atividades vinculadas à borracha, aliados às dificuldades do desenvolvimento de uma agricultura produtora de alimentos, impediram a diversificação produtiva da região amazônica. Assim, o suposto complexo econômico regional não se consolidou. A cidade de Manaus funcionou apenas como entreposto comercial e residência das famílias britânicas ou da elite local com seus sofisticados padrões de consumo e hábitos culturais para a época, como ilustra o Teatro de Manaus e sua casa de chá para as senhoras inglesas e para a elite local.

No início do século XX a concorrência com a borracha da Ásia, especialmente da Malásia, provocou a queda nos preços, e consequentemente da produção, levando a economia da região amazônica a grande crise. Parcela da população nordestina transferida para a região amazônica foi abandonada, não tendo como regressar aos seus estados de origem, não apenas pela distância, mas também pelo proibitivo preço dos transportes para uma população que praticamente não tinha renda monetária e que passara a viver na subsistência predominantemente extrativista. Por uma questão de controle político do território, houve, a partir de 1904, a criação de vários territórios na região amazônica, sob a administração direta do Governo Federal. Mais recentemente, esses territórios foram posteriormente transformados nos atuais estados de Rondônia, Acre, Roraima e Amapá.

\subsection{A tardia expansão econômica do sul do Brasil}

De maneira semelhante às demais experiências regionais no Brasil, a ocupação e o desenvolvimento do sul do Brasil, até o século XIX, ocorreu de forma lenta e rarefeita, predominantemente no litoral dos três estados. No século XVIII, estabeleceu-se certo comércio entre o Rio Grande do Sul e a região das Minas Gerais, especialmente de animais de carga (equinos e muares), importantes durante o ciclo do ouro, pois a tropa era fundamental para garantir o fluxo de ouro em direção aos portos (notadamente Paraty, RJ), e o abastecimento necessário à região mineradora. No entanto, a crise da mineração praticamente eliminou esse comércio.

Mais tarde foram ocupadas as áreas planas do Rio Grande do Sul onde se desenvolveu a pecuária bovina e ovina. A bovina deu origem às charqueadas e à exportação de carne, sebo e couro. A ovina deu origem à exportação de lã. Houve também a expansão da produção de erva mate nos três estados do Sul, que chegou a ser importante produto de consumo regional e exportação, principalmente para o Uruguai e Argentina.

(3) Percival Farquhar assumiu o controle do Porto do Pará e todo o sistema de navegação do Rio Amazonas, controlando o sistema de transporte, além de haver recebido outros benefícios, como a doação de $60 \mathrm{mil} \mathrm{km}^{2}$ de terras pelo Governo do Pará (Castro, 1979, p. 113-114). 
A partir da segunda metade do século XIX, a imigração europeia para a região, especialmente de alemães, italianos e poloneses, deu uma nova dinâmica à economia regional. Além da expansão da pecuária na região pampiana, houve a crescente ocupação das serras gaúchas, do oeste de Santa Catarina e parte do Paraná, com o desenvolvimento da agricultura, inclusive vinícola. No início do século XX, a expansão da cafeicultura paulista atingiu o norte do Paraná.

No início, essas atividades não conseguiram atingir um dinamismo suficiente para gerar divisas e condições que permitissem uma expansão e diversificação produtiva que desse destaque à integração e crescimento econômico da região. No entanto, com a chegada dos imigrantes ampliouse a diversificação da agricultura e começou a surgir um empresariado regional em atividades industriais, especialmente dos imigrantes alemães e italianos e seus dependentes. São exemplos, dentre outras: Hering (1880), Gerdau (1901), Aurora (1931), Perdigão (1934), Marco Polo (1949), Weg (1961), além de várias outras nos setores de couros, calçados, etc. Essa diversificação ajuda a explicar sua expansão a partir da segunda metade do século XX e sua integração com a indústria paulista.

\subsection{Minas: a controvertida interpretação de seu desempenho}

A interpretação do desempenho econômico de Minas Gerais foi sempre complexa e objeto de grande debate na historiografia econômica brasileira. Furtado (1959), em "Formação Econômica do Brasil" alega a falta de desenvolvimento endógeno e a incapacidade técnica dos imigrantes em desenvolver atividades manufatureis como sendo responsáveis pela não diversificação da economia mineira (Furtado, 1959, p. 87).

Cano (1977), em "Raízes da Concentração Industrial em São Paulo", tratou de todas as regiões brasileiras, mas não de Minas Gerais. O livro inclui, apenas em seu final, a indicação de que Minas Gerais era complementar a São Paulo, fornecendo bens de origem agropecuária e industriais de consumo, matérias primas minerais e produtos intermediários, porém a partir do século XIX. Em seu novo livro, "Desequilíbrios Regionais e Concentração Industrial no Brasil 1930-70", volta à análise da dinâmica de todas as regiões brasileiras, à exceção de Minas Gerais. Talvez porque, embora modesta, Minas Gerais foi o único estado brasileiro que não perdeu participação na produção industrial durante o processo de concentração em São Paulo.

Mais tarde, em seu "Ensaios sobre a Formação Econômica Regional do Brasil", publicado em 2002, Cano analisa, em seu capítulo 1, a economia do ouro em Minas Gerais no século XVIII e o desempenho econômico no estado nos séculos XIX e XX. Diz que o capítulo havia sido escrito como parte de sua tese de doutoramento, que deu origem ao livro "Raízes", mas que após críticas decidiu não o incluir na tese. Alega, inclusive, que o assunto lhe parecia haver sido tratado de forma conclusiva por Furtado (1959) em "Formação Econômica do Brasil".

Em seu novo texto, retoma o assunto. Resgata as análises de Furtado (1959) e acrescenta o argumento de que não haveria excedente retido em Minas. Ao contrário Castro (1971, p. 33-46) mostra que a economia do ouro criou concentrações urbanas, significativa população livre e, portanto, mercado interno. O que impediu o desenvolvimento da manufatura foram as draconianas medidas da metrópole, a exemplo da Carta Régia de 1715 e do Decreto de Dona Maria I de 1785. O primeiro proibindo a implantação de engenhos, e o segundo a implantação e funcionamento de fábricas. 
Simultaneamente, houve a perseguição aos Inconfidentes, que tinham projeto de diversificação econômica, com abolição da escravidão, implantação de uma casa da moeda, fábricas de pólvora, ferro, tecidos e outras manufaturas (De Paula, 2018). Nessas condições, a crise da mineração e a perseguição política selaram a possibilidade da diversificação econômica.

Castro (1971) enfatiza que no século XVIII Minas Gerais era predominantemente urbana e possuía grande contingente de população livre, constituindo-se portando um importante mercado interno. Houve também altíssimo volume de recursos retidos na região, como comprovam as sofisticadas construções Habitacionais, para os padrões da época, as obras religiosas e de arte que continuam preservadas nas cidades coloniais mineiras. Havia, portanto, grande volume de excedentes retidos na região. O que não havia era liberdade para sua aplicação em atividades de diversificação econômica.

Adicionalmente, Cano se apoia em Novais (1969) e Cardoso de Melo (1982) para negar a possibilidade de industrialização na Minas do século XVIII. Esses autores não o auxiliam em sua análise. Ao contrário, Novais reforça a posição de Castro (1979), exatamente pelo controle da metrópole sobre a colônia, o exclusivo do comércio e a escravidão. A análise de Cardoso de Melo (1982), por outro lado, pouco acrescenta à análise sobre a questão mineira, pois se refere ao século XIX, ou seja, outro período histórico. Ainda que o café tenha atingido as regiões leste e sul do estado de Minas Gerais, não teve aqui a mesma pujança observada no planalto paulista.

Novamente, há controvérsias na interpretação sobre o desempenho da economia mineira nos séculos XIX e XX. Com a crise da mineração, parcela da população foi migrando para o interior, vivendo de atividades de subsistência ou criando a denominada "fazenda patriarcal mineira", com predominância de pecuária e atividades de subsistência, dando inclusive a falsa intepretação de feudalismo.

Martins (2018), defende uma tese alternativa, a de que Minas Gerais estaria crescendo em silêncio. Baseia sua tese ao analisar as exportações de Minas Gerais, e no grande contingente de escravos em Minas Gerais durante o século XIX. A explicação estaria nas atividades de abastecimento de bens de consumo para a capital do império - à época a cidade do Rio de Janeiro -, e para o abastecimento de parte do estado de São Paulo, facilitado pela sua proximidade a essas regiões. O Rio de Janeiro, capital da colônia e depois do país, pela sua dimensão populacional para a época e pelo seu mercado de consumo. São Paulo, pela expansão do complexo cafeeiro com trabalho assalariado e pelo crescimento urbano.

Adicionalmente, embora escravista, a cafeicultura do leste mineiro proporcionou um relativo crescimento regional, como indica a formação da rede urbana da região e o papel da estrada de ferro Leopoldina, vinculando a região da mata mineira à cidade do Rio de Janeiro.

\subsection{O café escravista do vale do Paraíba e do leste mineiro e a incapacidade da cidade do Rio de Janeiro de exercer o papel de centro polarizador do país}

O caso do Vale do Paraíba e do Leste mineiro foram analisados de forma distinta por Cano (1977). A produção de café no Vale do Paraíba fluminense e paulista cresceu de forma lenta, ao longo do século XIX, atingindo seu pico por volta de 1880. A partir daí, a competição com o oeste paulista, 
a deterioração das terras e as relações escravistas dificultaram sua expansão. Somando-se a produção do leste mineiro à do Vale do Paraíba, na virada do século XIX para o XX, esta já não correspondia a um terço da produção do oeste paulista. A partir daí, o café escravista de Minas e do Vale do Paraíba entraria em declínio.

Além das relações escravistas, que impediam a formação de um mercado regional de bens de consumo, especialmente de uma agricultura mercantil de alimentos, as atividades comerciais, financeiras e de outros serviços estavam na cidade do Rio de Janeiro. Não se formaram, assim, relações interindustriais que exercessem efeito multiplicativo na economia regional. Isto fica claro, inclusive, com a relativa estagnação da cidade de Juiz de Fora, então conhecida como a "Manchester Mineira"4 . Nesse sentido, a inauguração da Estrada de Ferro Leopoldina, em 1874, drenou as relações do leste mineiro para a cidade do Rio de Janeiro e esvaziou o papel de Juiz de Fora como centro econômico da região.

Com o aumento dos preços no início do século XX, o café se expandiu para o Espírito Santo, Sul de Minas, porém apenas como atividade primária exportadora, sem criar maiores vínculos intersetoriais.

Há, por outro lado, um paradoxo no desempenho econômico da cidade do Rio de Janeiro. Sede do Império e da República e, portanto, da burocracia pública, centro comercial e base exportadora, a cidade do Rio de Janeiro não foi capaz de assumir a liderança econômica do país.

A dispersão geográfica do país e a existência de diferentes experiências primárioexportadoras na maioria das regiões criaram, inicialmente, uma tênue industrialização descentralizada, como mostra Castro (1991). No entanto, houve uma relativa concentração na cidade do Rio de Janeiro. Em 1907, o primeiro censo industrial do país indicou que o Rio de Janeiro participava com 33\% da produção industrial do país, São Paulo com 16\% e a restante distribuição nos demais estados. Em 1920, a participação do Rio de Janeiro havia caído para 20\%, enquanto a participação de São Paulo havia dobrado, atingindo 32\% da produção industrial brasileira. Dentre as diferentes interpretações da incapacidade do Rio de Janeiro em assumir o papel de centro polarizador da economia nacional, Lessa (2000) destaca a herança histórica da cidade, seu papel como capital e a posterior perda da centralidade. Acrescentamos a esses valores, de forma semelhante, as experiências da burguesia comercial que não foi capaz de dar um salto para uma burguesia industrial e financeira (Leopoldi, 2000). Assim, a herança histórica do Rio de Janeiro tinha criado uma elite e não uma burguesia, o que explicaria a dificuldade de sua expansão e diversificação econômica e suas recorrentes crises econômica, social e política.

\section{A contínua força aglomerativa da economia paulista}

A partir da década de 1980, a hipótese de reversão da polarização da Região Metropolitana de São Paulo ganharia destaque na literatura e no debate sobre a questão regional brasileira (Townroe; Keen, 1984; Azzoni, 1986; Storper, 1991). Todos eles, com argumentos diferenciados, negaram o fenômeno. Townroe e Keen (1984) tomaram como referência apenas a concentração populacional e

(4) No final do século XIX, a partir da montagem de duas indústrias têxteis e da primeira usina hidrelétrica da América do Sul, a imprensa local e alguns políticos passaram a se referir a Juiz de Fora como Manchester Mineira. 
não econômica. Azzoni (1986) concluiu que a desconcentração da RMSP estaria retida em seu campo aglomerativo, por ele entendida como contido em um raio de 150 quilômetros. Storper (1991) tomou os dados do estado de São Paulo e não de sua área metropolitana. Ao contrário, Diniz (1982), tomando como base a análise das decisões de investimento ocorridas a partir da década de 1970 e da defasagem entre decisões e materializações de investimento, e destes com os resultados produtivos, demonstrou que o estado de São Paulo estava tendo forte perda nessas decisões, indicando que, no futuro, o estado e sua área metropolitana perderiam participação na produção. Essa hipótese foi confirmada pelos dados dos Censos Industriais, mostrando que a participação da RMSP na produção industrial brasileira havia caído de $44 \%$ em 1970 para $26 \%$ em 1990 e o total do estado de São Paulo de $58 \%$ para $49 \%$. Ao mesmo tempo, o interior do estado aumentou sua participação de $14 \%$ para $26 \%$ do total estadual. Esse aumento, no entanto, não compensava a perda da área metropolitana, indicando que além do crescimento da produção no interior do estado, estava havendo crescimento em outras regiões do país.

Análises mais apuradas, tomando as microrregiões geográficas (Diniz, 1993; Diniz; Crocco, 1996) indicaram que estaria havendo a combinação da desconcentração da Região Metropolitana de São Paulo com uma aglomeração macroespacial no que o autor denominou desenvolvimento poligonal no Brasil, formado aproximadamente pelas microrregiões contidas no polígono Belo Horizonte-Uberlândia-Londrina/Maringá-Porto Alegre-Florianópolis-São José dos Campos-Belo Horizonte. Esse polígono, excluída a participação da RMSP, teria aumentado sua participação na produção industrial de $33 \%$ para $51 \%$ do total nacional, indicando a combinação da reversão da polarização da RMSP com a aglomeração macroespacial. Nessa ampla região vem ocorrendo também a ampliação da integração dos segmentos industriais tecnologicamente mais modernos, com maior integração e maiores ligações interindustriais e mais complexos.

Ao mesmo tempo, se verificam algumas mudanças complementares e correlacionadas com a perda da RMSP na produção industrial, com ampliação de suas funções como principal centro econômico nacional, concentrando o setor financeiro e mercado de capitais, sedes empresariais, atividades comerciais e de serviços, atividades educacionais e de pesquisa, medicina avançada, atividades culturais, etc. Estas características mudam a visão clássica de desindustrialização com perda de outras atividades, como ocorreu nos casos clássicos de desindustrialização do nordeste dos Estados Unidos e norte da Inglaterra (Bluestone; Harrison, 1982; Massey; Meegan, 1982). Esse movimento amplia o alargamento da região metropolitana de São Paulo, com o fortalecimento econômico de uma rede de cidades próximas, formando um grande adensamento em um raio de aproximadamente 100 quilômetros, no qual se incluem as regiões de Campinas, Sorocaba, São José dos Campos e sua integração portuária com os portos de Santos e São Sebastião (Diniz; Campolina, 2004; Proença; Santos Jr., 2019).

Destacam-se, também, as atividades agroindustriais na parcela oeste dos estados do Rio Grande do Sul, Santa Catarina, Paraná e São Paulo e seu movimento de integração e complementaridade com a agroindústria dos estados de Mato Grosso do Sul e Goiás.

Esse fenômeno indica uma característica semelhante àquela analisada por Furtado no GTDN (1967), ao caracterizar a região centro-sul do país como a mais desenvolvida. Essa agora se alarga, incluindo o Centro-Oeste do país. Nesse sentido, a proximidade geográfica e produtiva facilita a 
integração, na linha defendida por Cano (1977) como complexo econômico regional ampliado. Ficam, porém, excluídos os estados do Espírito Santo, Rio de Janeiro, leste e norte de Minas Gerais e metade sul do Rio Grande do Sul (Diniz; Mendes, 2021).

Não se pode negar, no entanto, o crescimento econômico do Nordeste nos últimos anos. Este pode ser explicado, principalmente, pelo crescimento industrial e incorporação produtiva dos cerrados da região e dos projetos de irrigação do vale do São Francisco e da região de Mossoró. O crescimento industrial se baseou em dois processos. O primeiro, pela transferência de atividades industriais do sudeste e do sul do país, na busca de incentivos fiscais e trabalho mais barato, especialmente têxtil, confecções e sapatos. O outro, pela localização de grandes projetos industriais, decorrentes do sistema de incentivos fiscais, de decisões políticas e de melhoria da infraestrutura. O primeiro parece haver se esgotado. O segundo corre grande risco caso o governo não mantenha essa prioridade e abandone alguns projetos em implantação ou ainda não consolidados, a exemplo de estaleiro, refinarias, petroquímica, ferrovia transnordestina, entre outros.

\section{Complexo econômico versus complexidade econômica: enriquecimento quantitativo e empobrecimento analítico}

Em anos recentes, o conceito de complexidade vem ganhando espaço nas diversas áreas das ciências sociais, inclusive na econômica. Essa concepção foi importada dos sistemas dinâmicos da física, superando a concepção estacionária e de equilíbrio da própria física newtoniana.

Em economia, eles se originaram dos seminários organizados pelo Instituto Santa Fé, com participação de cientistas da natureza e economistas (Anderson et al., 1987). A partir deste seminário, Arthur (1987), partindo do pressuposto de que a economia não é orientada por um equilíbrio e nem por agentes racionais, mas por um sistema complexo e dinâmico, introduziu a concepção da complexidade. Para o autor, a introdução dessa perspectiva daria à ciência econômica um arcabouço matemático e metodológico mais adequado aos diversos problemas que a teoria econômica convencional não era capaz de tratar adequadamente. Nos últimos anos tem ocorrido um amplo debate sobre a possibilidade de que a complexidade econômica se torne um referencial para o futuro da ciência econômica como apontam Holt, Rosser Jr. e Colander (2011). Eles argumentam que a complexidade pode se transformar em um paradigma capaz de guiar o futuro da economia.

A partir dessa nova formulação, e sustentado no avanço dos sistemas computacionais e na disponibilidade de dados estatísticos, Hausmann e Hidalgo (2011) desenvolveram e divulgaram o denominado The Atlas of Economic Complexity: mapping paths to prosperity. Nesse trabalho, tomando a estrutura produtiva dos países e a pauta de exportações de cada um, demonstraram que quanto mais complexa e, portanto, diversificada e integrada a estrutura produtiva de um país, mais desenvolvida e maior é sua capacidade de exportação e competição.

A partir daí, generalizaram-se os estudos da complexidade, transformando-os em verdadeira panaceia e com a proposição de que essa metodologia poderia constituir uma nova teoria econômica geral, servindo para medir e explicar, entre outros, diferenças de renda entre nações, desempenho econômico, capacidade de exportação, desigualdades sociais da renda, desigualdade de gênero, meio ambiente e outros temas (Hidalgo, 2021). 
A incorporação de visões cientificas das diversas áreas do conhecimento é algo importante e que deve ocorrer, inclusive, na busca por uma maior interdisciplinaridade analítica para temas transdisciplinares. Livro organizado por Colander (1998) procura destacar como a questão da complexidade já estava presente no pensamento econômico, ainda que não tivesse sido incorporada dentro de um arcabouço matemático. A relação da economia e as influências da biologia e da física também têm sido objetivo de debate na evolução da teoria econômica (Carvalho; Cardoso, 2021).

Entendemos, no entanto, que cada área do conhecimento deve preservar as raízes e a essência de seu objeto. No caso da economia, a mesma deve ser ancorada na economia política. Essa tinha, desde o seu nascimento, o objetivo básico do entendimento e análise do funcionamento dos sistemas econômicos, da dinâmica de suas estruturas produtivas e dos conflitos distributivos, combinando, analiticamente, as dimensões ou condicionantes internacionais, técnicos, sociais, políticos e ambientais, como ilustram as obras dos autores clássicos e seus seguidores (Smith, 1776; Ricardo, 1817; Marx, 1867). Dessa forma, a economia não pode ser tratada como uma ciência exata. Ainda que seja útil e necessário, a simples incorporação de modelos matemáticos complexos e flexíveis, não conseguirão jamais responder a todas as interações sociais, políticas e econômicas, e as contradições e dimensões culturais, simbólicas e qualitativas da natureza e do comportamento humano. Portanto, em que pesem os avanços metodológicos e de paradigmas, entendemos que a dialética continua sendo central para a análise dos processos de desenvolvimento econômico. Assim, entendemos que a combinação dos avanços metodológicos deve estar sempre articulada em uma perspectiva de que o todo seja analisado.

No caso do Brasil, essa linha metodológica da complexidade vem sendo incorporada e difundida nos últimos anos (Gala, 2017; Freitas, 2019; Brito et al., 2019; Hartman et al., 2021; Freitas et al., 2021), entre outros. A nosso ver, o uso dessa metodologia deve ser feito de maneira complementar à análise, considerando as características e as especificidades históricas e estruturais de cada país ou região

A primeira questão se refere à relação entre complexidade e capacidade de exportação. Ao contrário das economias da Alemanha, Japão e Coreia, normalmente referidas como as mais eficientes, o Brasil é um país com grande dimensão e diversidade territorial, com uma formação histórica e social únicas, características econômicas e níveis de integração muito diferenciados, os quais precisam ser incorporados na análise.

Nossa industrialização, ao contrário dos países mencionados, além de tardia e dependente, teve forte presença de empresas estrangeiras, cujas estratégias de diversificação e integração são dependentes das suas estratégias globais e de suas matrizes. Como mostra Franzylber (1983), os limites da industrialização latino-americana decorreram da cópia do padrão de consumo, da reprodução de instituições e do modelo industrial dos países centrais. O autor compara os modelos de industrialização latino-americano e do sudeste asiático, procurando apontar como no caso do segundo, a industrialização ocorreu de forma complementar e diversa daquela observada nos países centrais. Ainda hoje, entre outros, a dimensão geopolítica continua sendo uma das condicionantes centrais.

O primeiro aspecto para o qual é preciso chamar atenção diz respeito à utilização dos dados de exportação para mensurar a complexidade produtiva de um país. Em muitos casos, principalmente 
em países com economias muito grandes ou menos abertas internacionalmente, as exportações constituem apenas uma fração da produção destes países. Assim, a complexidade medida a partir dos produtos e setores que exportam, deixam de captar o tamanho do mercado interno dos países, o que em vários casos é algo muito importante, principalmente naqueles países onde o mercado interno possui tamanho e escala consideráveis. Parte das recomendações de Hausmann et al. (2017) para o Panamá, por exemplo, claramente não são adequadas a um país da dimensão do Brasil. A forma como o autor trata o investimento estrangeiro direto e as empresas multinacionais também merece uma discussão mais aprofundada. Gala (2017) tece críticas à visão institucionalista sobre o tema. O exemplo recente da China mostra que, claramente, a abertura da conta de capitais e a presença de empresas multinacionais foi feita dentro de rigoroso controle político, demostrando claramente como o tema possui muitas mais facetas e aspectos que precisam ser considerados, dentro de uma lógica que integre o modelo matemático e uma visão dialética dos processos.

Nesse sentido, a tentativa de um projeto nacional na linha proposta e implementada pela era Vargas foi quebrado com a opção pela internacionalização aberta na era JK, como mostram Mirra e Salerno (2015). Embora o Brasil tenha avançado em seu processo de industrialização, especialmente no período 1950-1980, essa expansão se mostrou dependente das empresas estrangeiras, induzindo os padrões de demanda e consequente consumo dos países centrais, o que tolheu a autonomia do país (Furtado, 1974; Franzylber, 1983). Mais recentemente, a combinação do boom das commodities, a sobrevalorização do real, a política tributária e a menor produtividade têm provocado uma rápida desindustrialização (Moceiro, 2019). Assim, o esforço de diversificação produtiva ensaiado na década de 1970, com o desenvolvimento da indústria de bens de capital, se frustrou.

A comparação com o caso Coreano, ressaltado por Brito et al. (2019) precisa ser qualificada. Sem nenhum demérito ao esforço interno daquele país, o sucesso do crescimento industrial e da expansão das exportações daquele país se fez dentro de condicionantes históricos e uma inserção externa que foram decisivos para explicar sua trajetória de desenvolvimento. Em primeiro lugar, a ocupação japonesa ocorrida entre 1910-45 levou base produtiva moderna para a Coréia, como ilustra a experiência da organização dos complexos industriais através do Chebol, que são uma réplica da experiência dos Keitsu japoneses. Em segundo lugar, por uma questão da geopolítica dos Estados Unidos e do capitalismo contra a ameaça comunista, os mercados ocidentais foram abertos aos produtos coreanos, sem presença de empresas estrangeiras naquele país, e com uma estratégia de engenharia reversa explícita e consentida. Em terceiro lugar, os Estados Unidos apoiaram de forma direta e explícita o desenvolvimento tecnológico, tendo financiado e apoiado a criação do KIST (Korean Institute of Science and Technology), conjunto de laboratórios que sustentaram o desenvolvimento tecnológico e industrial daquele país em articulação direta com o sistema empresarial e acadêmico universitário e as políticas públicas (KIST, 2019; 2019a; STEPI, 2019). Segundo nossa intepretação, a montagem de institutos equivalentes no Vietnam e no Camboja, pelo KIST, com apoio americano, visa fortalecer o colar econômico protetor dos Estados Unidos e da própria Coreia contra a competição chinesa. Badcock (2007) argumentou que, a despeito dos avanços da complexidade econômica, o desenvolvimento econômico deve continuar sendo pensado com características particulares de cada país em um determinado tempo histórico. A complexidade ajudou a equacionar a questão da linearidade presente nos autores clássicos do desenvolvimento, sejam a 
corrente marxista, sejam os autores ligados à escola desenvolvimentista do pós-guerra como Rostow, ou mesmo a visão mais recente do Consenso de Washington.

Em uma tentativa de lidar com a restrição imposta pelo uso das exportações, Sousa (2018) aplica o conceito de complexidade para a base de dados da World Input-Output (WIOD) procurando apontar sua melhor adequabilidade e robustez à aplicação da complexidade. $\mathrm{O}$ autor enfatiza a centralidade da indústria na geração de inovações e aumento da complexidade, procurando apontar os gargalos e limites impostos por fatores que acabam bloqueando a continuidade do processo de desenvolvimento.

Gala (2017), em uma síntese sobre o tema, aponta como perspectivas críticas são importantes para uma melhor compreensão da questão ligada à complexidade, procurando agregar à sua análise aspectos ligados à macroeconomia e a uma abordagem de inspiração estruturalista, mostrando os diferentes bloqueios ao aumento da complexidade. Destaca, dentre outros, a centralidade da inovação principalmente no setor de bens de produção, que determinam a autonomia não só do restante do setor industrial como do conjunto da economia, algo que vem sendo apontado pelos economistas estruturalistas há muito tempo.

Carvalho e Cardoso (2021) demonstram como dois economistas estruturalistas da escola da Cepal, o brasileiro Celso Furtado e o mexicano Juan Noyola Vásquez, já incorporavam nas suas visões uma perspectiva da complexidade. Em que pese não ser objeto deste trabalho, analisando a obra de outros economistas cepalinos, é possível vislumbrar elementos da complexidade em outros autores da escola estruturalista como Franzylber (1983).

É nesse sentido, do resgate de uma visão estruturalista, como faz Cano (1977), que o conceito e análise dos complexos econômicos deve ser resgatado. Caso contrário, corre-se o risco de que a adoção de políticas econômicas de fomento ao setor industrial e à inovação que sejam fracassadas. Muito além de medir, o autor estabelece os encadeamentos entre os fatores econômicos, políticos, sociais e geográficos para explicar a trajetória do desenvolvimento paulista e as limitações à trajetória verificadas em outras regiões.

Assim, tendo em mente uma das principais funções do economista, que é pensar e guiar uma agenda de desenvolvimento, o trabalho de Cano (1977) fornece elementos importantes para pensar não apenas a política econômica, mas a necessidade de que ela seja articulada com variados aspectos necessários à transformação socioeconômica de um país, em linha com a visão de Badcock (2007).

\section{Referências bibliográficas}

ANDERSON, P. W.; ARROW, K. J.; PINES, D. The economy as an evolving complex system. Santa Fe Institute Studies in the Science of Complexity, Proceedings, v. V. Reading, MA: Addison-Wesley, 1988.

ARTHUR W. B. Self-reinforcing mechanisms in economics. In: ANDERSON, P. W.; ARROW, K. J.; PINES, D. (Ed.). The economy as an evolving complex system. Santa Fe Institute Studies in the Sciences of Complexity, Proceedings, v. V. Redwood City, CA: Addison-Wesley, 1988. 
ARTHUR, W. B. Self-Reinforcing Mechanisms in Economics' in: Anderson, P. W; Arrow, K. J; Pines, D. The Economy as an evolving complex system. Proceedings, v. V. Santa Fe Institute Studies in the Science of Complexity, Reading, MA: Addison-Wesley, 1988.

ARTHUR, W. B.; DURLAUF, S. N.; LANE, D. A. (Ed.). The economy as an evolving complex system II. Santa Fe Institute Studies in the Science of Complexity, Proceedings, v. XXVII. Reading, MA: Addison-Wesley, 1997;

AZZONI, C. R. Indústria e reversão da polarização no Brasil. São Paulo: IPE-USP, 1986.

BADCOCK, Abbie. Can complexity save development theory? In: BOGG, Jan; GEYER, Robert (Ed.). Complexity, science and society. New York: Radcliffe Publishing, 2007.

BLUESTONE, B.; HARRISON, B. The desindustrialization of America: plant closing, community abandonment and dismantling of basic industry. New York: Basic Books, 1982.

BRITTO, G.; ROMERO, J. P.; FREITAS, E.; COELHO, C. The great divide: economic complexity and development paths in Brazil and the Republic of Korea. Cepal Review, v. 127, p. 191-213, 2019.

CANO W. Raízes da concentração industrial em São Paulo. Difel, 1977.

CANO, W. Ensaios sobre a formação econômica regional do Brasil. Campinas: Editora Unicamp, 2002.

CARDOSO DE MELO, J. M. O capitalismo tardio. São Paulo: Brasiliense, 1982.

CARVAlHO, A. R.; CARDOSO, F. G. Elementos de complexidade na economia do desenvolvimento de Furtado e Noyola. Economia e Sociedade, Campinas, v. 30, n. 1(71), p. 91-114, jan./abr. 2021.

CASTRO, A. B. Sete ensaios sobre a economia brasileira. Forense, 1969. v. I.

CASTRO, A. B. Sete ensaios sobre a economia brasileira. Forense, 1971. v. II, cap. 4.

CASTRO, A. C. As empresas estrangeiras no Brasil, 1860-1913. Zahar, 1979.

COLANDER, David. Complexity and the history of economic thought: perspectives on the history of economic thought. Selected papers from the History of Economics Society Conference. New York: Routledge, 2000.

DE PAUlA, J. A. Minas no século XVIII. In: RABÊLO, J. M. (Coord.). História Geral de Minas. 1. ed. Ouro Preto, MG: Livraria \& Editora Graphar, 2018.

DINIZ, C. C. Desenvolvimento poligonal no Brasil: nem desconcentração nem continua polarização. Nova Economia, v. 31, 1993.

DINIZ, C. C. Estado e capital estrangeiro na industrialização mineira. Belo Horizonte: UFMG/PROED, 1982.

DINIZ, C. C.; CAMPOLINA, B. A região metropolitana de São Paulo: reestruturação, reespacialização e novas funções. Eure, Santiago, v. 33, n. 98, 2007. 
DINIZ, C. C.; CROCCO, M. A. Reestruturação econômica e impacto regional: o novo mapa da indústria brasileira. Nova Economia, v. 6, 1996.

DINIZ, C. C.; MENDES, P. S. Tendências regionais da indústria brasileira no século XXI. Brasília, DF, IPEA, 2021. (Texto para Discussão, n. 2640).

FRANZYLBER, F. La industrialización trunca de América Latina. México: Centro de Economía Transnacional. Editorial Nueva Imagen, 1983.

FREITAS E. E. Indústrias relacionadas, complexidade econômica e diversificação regional: uma aplicação para microrregiões brasileiras. Tese (Doutorado)-Cedeplar/UFMG, 2019.

FREITAS, E. E. et al. Complexidade econômica e especialização inteligente: uma proposta de política de diversificação para o desenvolvimento de Minas Gerais. In: GUIMARÃES, A. Q. (Org.). Política pública e desenvolvimento em Minas Gerais. 1. ed. Curitiba: Appris, 2021.

FURTADO, C. Formação Econômica do Brasil. 1959

FURTADO, C. Mito do desenvolvimento. Rio de Janeiro: Paz e Terra, 1974.

GALA, P. Complexidade econômica. São Paulo: Contraponto, 2017.

GTDN. Uma política de desenvolvimento econômico para o Nordeste. 2. ed. Recife: Sudene, 1967.

GUILHOTO, J. J. M. Análise de insumo-produto, teoria e fundamentos. Munich personal RePEe Arcguvem. 2015. Disponível em: http://mPra.ub.uni.Munchen/de/id/eprint/32566.

HARTMANN, D.; GUEVARA, M. R.; JARA-FIGUEROA, C.; ARISTARÁN, M.; HIDALGO, C. Linking economic complexity, institutions, and income inequality. World Development, v. 93, p. 7593, 2017.

HAUSMANN, R., HIDALGO, C. et al. the Atlas of Economic Complexity. Hard, 2011.

HAUSMANN, R.; SANTOS, M. A.; OBACH, J. Appraising the economic potential of Panama: policy recommendations for sustainable and inclusive growth. Massachusetts: Center for International Development at Harvard University, 2017. (CID Faculty Working Paper, n. 334).

HIDALGO, C. A. Economic complexity theory and applications. Nat Rev Phys, 3, p. 92-113, 2021. Disponível em: https://doi.org/10.1038/s42254-020-00275-1.

HOLT, Richard P. F.; ROSSER JR., Barkley; COLANDER, David. The complexity era in economics. Review of Political Economy, v. 23, n. 3, p. 357-369, 2011. DOI: 10.1080/09538259.2011.583820.

KIST. The Kist Story - the birthplace of Korea's industrial development. KIST, 2019.

KIST. Kist 2066, beyond the Miracle. 2019a.

LEOPOLDI, M. A. Política e interesses a industrialização brasileira. Rio de Janeiro: Paz e Terra, 2000.

LESSA, C. O Rio de todos os Brasis: uma reflexão em busca da autoestima. Rio de Janeiro: Record, 2000.

LIMA, J. H. Café e indústria em Minas Gerais. Vozes, 1981. 
MARTINS. R. Crescendo em silêncio. A incrível economia escravista de Minas Gerais no século XIX. ICAM/ABPHE, 2018.

MARX, Karl (1867). O Capital: crítica da economia política. São Paulo: Abril Cultural, 1983. v. I, t. 1. (Coleção os Economistas).

MASSEY, D. MEEGAN, R. The anatomy of job loss, the how, why and where of employment decline. London: Metghen, 1982.

MIRRA, E.; SALERNO, M. S. ABDI: o que veio, a que ficou. In: ABDI. Dez anos de política industrial: balanço e perspectivas. ABDI, 2015.

MOCEIRO, P. C. A indústria brasileira no limiar do século XXI: uma análise de sua evolução estrutural, comercial e tecnológica. Tese (Doutoramento)-USP, 2019.

NOVAIS, Fernando A. O Brasil nos quadros do Antigo Sistema Colonial. In: NOVAIS, F. A. Brasil em Perspectiva. São Paulo: DIFEL, 1969.

PROENÇA, A. D. de A.; SANTOS JUNIOR, W. R. dos. Reestruturação produtiva e consolidação de novos eixos de desenvolvimento territorial: o caso do vetor de desenvolvimento perimetral da macrometrópole paulista. Revista Brasileira de Estudos Urbanos e Regionais, v. 21, n. 2, p. 312-328, maio/ago. 2019.

RICARDO, David. (1817). Princípios de economia política e tributação. São Paulo: Abril Cultural, 1982. (Coleção Os Economistas).

SILVA, S. Expansão cafeeira e as origens da indústria no Brasil. São Paulo: Alfa-Omega, 1976.

SIQUEIRA, T. V. As primeiras ferrovias do Nordeste brasileiro: processo de implantação e o caso da Great Western Railway. Revista do BNDES, Rio de Janeiro, v. 9, n. 17, 2002.

SMITH, Adam. (1776). A riqueza das nações: investigação sobre sua natureza e suas causas. São Paulo: Abril Cultural, 1983. (Coleção Os Economistas).

SOUSA, R. A. A teoria da complexidade reencontra o desenvolvimento econômico - Uma análise de insumo-produto. Dissertação (Mestrado)-Universidade de Brasília, Brasília, 2018.

STEPI - Science \& Technology Innovation Policy for the People-s Life, 2019.

STORPER, M. Industrialization, economic development, and the regional question in the third world: from import substitution to flexible production. New York: Pion, 1991.

TOWNROE, P. M.; KEEN, D. Polarization reversal in the State of São Paulo, Brazil. Regional Studies, v. 18, n. 1, 1984.

VIEIRA, D. J. Complexo econômico e variedades de desenvolvimento regional: uma interpretação da crise contemporânea de Minas Gerais. In: QUINTELA, A. et al. Wilson Cano e a economia regional. São Paulo: Fundação Perseu Abramo (No prelo). 